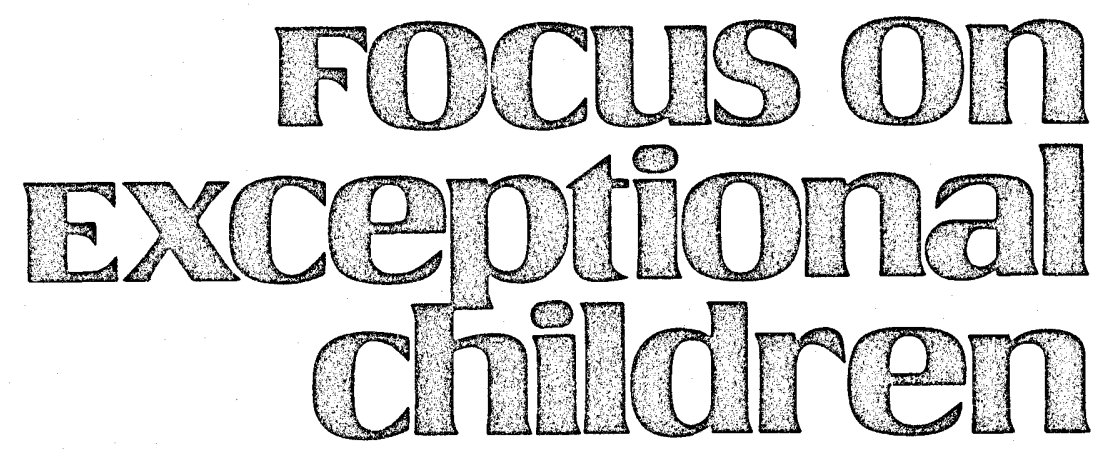

\title{
A University-Based Model of Multidisciplinary Services to Exceptional Students and Related Professionals
}

\section{Cecil D. Mercer, Susan K. Peterson, and John Ross}

Typically, the multidisciplinary team is school-based, composed of members designated in Public Law 94-142 who determine a student's eligibility for special services and arrive at a consensus for program placement and treatment recommendations. Multidisciplinary teams also are found in diagnostic centers, hospitals, or university settings and consist of professionals who focus on the comprehensive diagnosis of students. Traditionally, nonschool-based multidisciplinary programs have concentrated on assessment; few resources have been allocated for functions such as validating treatment recommendations, parent support, and follow-up consultation.

Evaluation data of multidisciplinary programs are limited (Armer \& Thomas, 1978; Pfeiffer, 1980), and evaluations that exist raise several important issues. For example, cost-effectiveness of multidisciplinary teams remains elusive (Barbrack, 1978); provision for technical assistance is minimal (Pryzwansky \& Rzepski, 1983); continuous consultative support to program implementers is not provided (Pfeiffer, 1980); staff development is not directly tied to team functions; and diagnosis as related to intervention is not stressed (Pfeiffer, 1980).

Moreover, participation of some team members is often limited, and the multidisciplinary effort becomes the product of a few team members who dominate the discourse. Yoshida, Fenton, Maxwell, and Kaufman (1977) report that regular teachers often perceive themselves as low in participation and low in satisfaction with the team process. Ysseldyke, Algozzine, and Allen (1981) assessed team meetings through analysis of videotapes and found that, on the average, teachers participated in $27 \%$ of the observed intervals. In 7 of 24 meetings teachers participated less than $10 \%$ of the interval (i.e., contributed less than 1 minute of talking).

These findings support the contentions that teachers often have little or superficial involvement in teams. Although some controversy exists concerning the benefits and functional outcomes of multidisciplinary teams, the potential merits of collaboration among professionals from various disciplines is apparent.

In 1981 the Florida State Legislature funded the University of Florida Multidisciplinary Diagnostic and Training Program (MDTP) to establish a university-based center of excellence to exemplify multidisciplinary teaming. Moreover, this team is directed to train university students, and to serve exceptional students, their teachers, and parents. MDTP is jointly administered through the Department of Pediatrics, College of Medicine, and the Department of Special Education, College of Education. The MDTP team consists of professionals from neurology, psychology, language, and special education and is directed by John J. Ross, Professor of Pediatric Neurology and Cecil D. Mercer, Professor of Special Education. This article presents a description of MDTP, the evaluation data collected on MDTP functions, and the implications of a university-based multidisciplinary team.

Cecil Mercer is a Professor, Department of Special Education, University of Florida, where Susan Peterson is an Assistant Professor. John Ross is a Professor in the Department of Pediatrics at the same university.

(C) Love Publishing Company, 1988. 


\section{DESCRIPTION OF MDTP}

The MDTP consists of a team of professionals serving children with diverse medical, behavioral, and learning problems. The referrals come from approximately 14 school districts that sign service agreements with MDTP each year. Since its inception in 1981, five main objectives have guided the program:

1. To set up a model program demonstrating a multidisciplinary, diagnostic-prescriptive approach to assist in evaluation and development of individualized education plans.

2. To provide preservice training to students in the colleges of Education, Medicine, and Health-Related Professions.

3. To institute an inservice program for teachers.

4. To offer a parent training program to parents of MDTP students and other interested parents.

5. To conduct and disseminate research related to program objectives.

\section{Focus on
Exceptional children}

FOCUS ON EXCEPTIONAL CHILDREN (ISSN0015-511X) (USPS 203-360) is published monthly except June, July, and August as a service to teachers, special educators, curriculum specialists, administrators, and those concerned with the special education of exceptional children. This publication is annotated and indexed by the ERIC Clearinghouse on Handicapped and Gifted Children for publication in the monthly Current Index to Journals in Education (CIJE) and the quarterly index, Exceptional Child Education Resources (ECER). It is also available in microform from Xerox University Microfilm, Ann Arbor, MI. Subscription rates: Individuals, $\$ 24$ per year; institutions, $\$ 30$ per year. Copyright (C) 1988 , Love Publishing Company. All rights reserved. Reproduction in whole or part without written permission is prohibited. Printed in the United States of America. Second class postage is paid at Denver, Colorado.

POSTMASTER: Send address changes to:

Love Publishing Company

Executive and Editorial Office

1777 South Bellaire Street

Denver, Colorado 80222

Telephone (303) 757-2579

EDITORIAL BOARD
Edward L. Meyen

University of Kansas

Richard J. Whelan

Glenn A. Vergason Georgia State University

University of Kansas Medical Center Senior Editor
The objectives represent a shift from the traditional multidisciplinary focus on diagnosis to a service/resource function that stresses a more systematic consideration of the child's total ecology. Thus, comprehensive diagnosis remains a function of the multidisciplinary team with collateral emphasis placed on (a) linking diagnosis to educational interventions, (b) increased parent involvement, (c) professional preservice and inservice training, and (d) follow-up to provide technical assistance and continuing support to long-term program implementers (Ross, Mercer, Hendrickson, Peterson, \& Hughes, 1985).

Brief descriptions of the basic components within the MDTP diagnostic-treatment procedure are presented next. These components include the initial referral, the MDTP team, the diagnostic clinic, the case conference, the diagnostic and training classroom, preservice training, inservice training, and the parent support group.

\section{The Initial Referral}

A parent, pediatrician, educator, school administrator, or other professional may initiate a referral to the MDTP. All referrals must be coordinated through the student's local school district. Each district has a cooperative agreement with the MDTP and an internal referral structure for setting referral priorities. Usually the coordinator of services for exceptional students of a school district distributes information on referral procedures to guidance counselors and school psychologists.

\section{The MDTP Team}

Each student referred to the MDTP is evaluated by members of a team composed of specialists from different disciplines. The core multidisciplinary team consists of professionals from the areas of special education, psychology, pediatric neurology, and speech and language pathology. Periodically other professionals are asked to participate on the team to help with children who have additional needs. These professionals may include social workers, child abuse specialists, physical therapists, and appropriate medical or mental health specialists.

\section{The Diagnostic Clinic}

The diagnostic clinic has two primary functions: (a) to provide short-term diagnostic services to assist in the identification of diverse learning, behavior and medical problems, and (b) to develop and recommend preventive, compensatory, and remedial intervention strategies (via the MDTP case conference). Typically, the diagnostic services are conducted over a 2-day period in which the student is evaluated at the University of Florida Health Center and at 
the College of Education. Students generally receive medi$\mathrm{cal} /$ neurological evaluations, vision and auditory screenings, speech and language assessments, an educational evaluation, which includes formal and curriculum-based assessments, and psychological evaluations, which may include achievement and intelligence testing as well as parent interviews and academic/behavioral assessments in the classroom.

The MDTP liaison consultant visits the student's school 1 to 3 weeks before the diagnostic clinic evaluation, to observe in the classroom, meet with the child's teachers, and review the cumulative folder. Information gained by the liaison is shared with other MDTP professionals who will test the child. The liaison consultant interviews the student's parent(s) while the evaluation is in progress. The case conference usually is scheduled a few days after testing, observation, and interviewing are completed.

\section{The Case Conference}

The basic purposes of the case conference are to share results of formal testing and informal assessments with local school district representatives and to generate plausible intervention strategies. Most often, the referral question(s) are: (a) does the child qualify for placement in a special program, (b) can specific recommendations be made for teaching the child, and (c) is there an underlying medical or psychological condition that accounts for the child's learning or behavior problems?

Many professionals involved with the referred child attend the case conference (e.g., local school district teachers and other district professionals, the multidisciplinary team members who tested the child, the MDTP staff liaison in charge of case coordination, and university students majoring in the respective MDTP disciplines.) The liaison consultant orchestrates the conference and follows a prearranged order of presentation. The conference begins with a statement regarding the purpose and procedures to be followed, an introduction of all team members, and a statement of specific purpose(s) for evaluating the student. The liaison presents teacher and parent concerns as well as data collected while visiting the child's school. School district personnel are asked to confirm, add to, or correct information presented by the liaison.

Subsequently, professionals from each discipline take about 5 minutes to describe salient aspects of their testing and interviews. They each present their findings via an overhead projector. After the formal presentation of results, the format changes to an open forum for discussion and brainstorming. The liaison facilitates team interaction and records the suggested recommendations on an overhead transparency. Before adjourning, the liaison reviews each recommendation and secures group consensus. Full written reports are delivered to the school district personnel and parents approximately 3 weeks after the case conference. All pertinent information is reviewed with the teachers and parents, and plans for any additional action are made.

For some children a decision is made to return them to their home school and to assign the MDTP liaison teacher to consult with local school personnel to implement the intervention plan. For others a decision is made to enroll them in the MDTP diagnostic and training classroom.

\section{The Diagnostic and Training Classroom}

If evaluation at the diagnostic clinic and case conference leads to questions that require more in-depth study, the diagnostic and training classroom is recommended for the student. This class is located in the College of Education, and students may attend it for 6 weeks. Typically, eight children are enrolled in the class, and the adult-student ratio is small. The class is staffed by special education teachers and a speech and language pathologist whose responsibilities include assessment and language instruction as well as training of inservice and preservice personnel. Children attending the class receive intensive treatment aimed at documenting effective teaching and behavior management strategies. Data-based instruction is used to determine the effectiveness of various instructional programs (e.g., reading, language, math, spelling, study skills) and various management techniques (e.g., point systems, contingency contracts, parent involvement).

When effective interventions are documented, the child's local school teacher visits the class to observe and learn the interventions. Then the child is returned to his or her local school, and the MDTP liaison teacher continues to consult with the teacher to implement the intervention plan. Much emphasis is placed on designing interventions that are feasible to implement in the local schools. Peer teaching, selfcorrecting materials, computer-assisted instruction, instructional games, self-management training, parent management training, and charting progress are some of the techniques that are used extensively (Mercer, 1987).

\section{Preservice Training}

Preservice training experiences are supervised by appropriate MDTP staff or university faculty, or both. These experiences, tailored to meet requirements or competencies the trainee needs, may include any combination of the following: (a) observation and hands-on experience (e.g., practicum) in the diagnostic and training classroom, (b) structured school visitations, (c) parent involvement activities, (d) educational, medical, psychological, and/or speech and language assessment, (e) assessment and intervention related to discipline and behavior managment, and ( $f$ ) observation and/or participation in the case conferences. 
Case conference participation frequently involves intern and pediatric residents as well as students studying in education, psychology, special education, speech pathology, and counseling. Typically, 3 to 4 preservice trainees are present at each MDTP case conference.

\section{Inservice Training}

Inservice training occurs at various sites (e.g., the school, the diagnostic classroom, the hospital), via university course offerings, in workshops and presentations offered at professional conferences, and through the participation of professionals working with the referred student in any or all of the MDTP functions.

Since inception of the MDTP, the case conference has been considered a vital training experience for teachers, counselors, school psychologists, speech pathologists, physicians, and other related professionals. An average of three local school district personnel attend each case conference. The distribution between regular and special education teachers usually is relatively equal. Administrators, guidance counselors, and school psychologists are represented approximately twice as often as either group of teachers.

\section{Parent Support Group}

Once a student has been referred to the MDTP, parent names are added to the MDTP parent list. They are advised of parent support meetings and encouraged to attend these gatherings. The parent support groups are based on the concept of "parent helping parent."

Parent support meetings, held approximately once a month, provide a forum for parents to present their concerns and problem-solve. Information exchange, the presentation of technical knowledge, and the sharing of child-rearing experiences characterize these informal group meetings.

Typically, the format of the monthly parent support group includes a large-group presentation that lasts 20-30 minutes. Afterward the parents divide into several small groups to identify specific concerns related to the evening's topic (e.g., discipline versus punishment, communication skills, building self-esteem, peer pressure).

In addition to parent support meetings, the liaison consultant provides prescriptive training and support to parents of MDTP children. Parents are invited to the diagnostic and training classroom to observe teaching and behavior management techniques. The liaison works with the parent to design programs for helping children succeed at home. Frequently parents focus on improving child behaviors such as doing homework, following directions, taking responsibility, showing respect, and getting along with others. Use of positive contingencies, contracts, ignoring, and other interventions may be planned with parents. Parental contact is main- tained between home and the MDTP via telephone and faceto-face conferencing. Additionally, the liaison may help to design and establish home-school contracts between the parents and the child's home-school teachers.

\section{EVALUATION OF THE MDTP}

Since its beginning in 1981, the MDTP has served more than 400 children, their parents or guardians, their teachers, and related school personnel. Of the children served, 209 have attended the diagnostic classroom from 3 to 6 weeks during the regular school year. Moreover, hundreds of university students have received preservice training through the MDTP. To improve services and determine the efficacy of the MDTP model, evaluation data have been collected across the various MDTP functions.

Data on teachers, students, and parents of children served in the diagnostic and training classroom 2 to 4 years prior to 1985 are reported. A random sample of data on 10 special education and 13 regular education/Chapter 1 teachers, 14 students, and 10 parents was gathered based on an initial drawing of 15 individuals in each category. Questionnaires were responded to anonymously by teachers and parents. Up-to-date information on students was obtained from examination of cumulative folders and parent feedback. Other evaluation data include an in-depth analysis of pre-posttest scores and daily precision teaching probes generated by learning disabled students who attended the diagnostic and training classroom between 1981 and 1987. Finally, questionnaire data from preservice students and from parents attending the parent program are presented.

\section{Services to Teachers and Parents}

Evaluation data collected from teachers and parents provide information on the quality of services across a variety of MDTP functions (e.g., case conference, diagnostic classroom, liaison services, and parent program). An evaluation of services to teachers and parents includes findings from an observational study of case conferences, a follow-up study of inservice teachers and parents, and feedback from parents who attended the parent program conducted in the evenings.

\section{Case Conference}

Because the case conference is the forum for sharing initial MDTP diagnostic findings and recommendations with teachers and team members, an evaluation of it is fundamental to examining the quality of diagnostic services, recommendations, and group dynamics. Also, decisions from the case conference are part of the recommendations shared with parents. 
A direct observational study was conducted on 10 randomly sampled MDTP case conferences to examine the interaction of team members. Data were collected on the number and percentage of initiations and responses made be members representing each subgroup of the team-medical, speech and language, psychological, educational, and local school district. The data were collected after all formal presentations of test results had been completed (i.e., during the brainstorm session). Observations ranged from 33 to 40 minutes. The results showed that no subcategory (e.g., psychological) dominated the brainstorm session. The range of subgroup participation varied from approximately $15 \%$ to $40 \%$ of the interactions in any given session with each subgroup participating in all sessions. Although the importance of active involvement by all members cannot be weighed precisely, the contention of Bass and Leavitt (1963) appears to be valid: People are more likely to carry out decisions they made or helped to make.

Of all teachers who referred students to the MDTP for evaluation, $85.7 \%$ attended their child's case conference. Table 1 presents data on teacher perceptions of MDTP case conferences. Of the randomly sampled teachers, the predominant response was positive in relation to five questions:

1. Was the conference a time for multidisciplinary exchange?

2. Did they have an opportunity to give input?

3. Was the session an active problem-solving occasion?

4. Was the case conference approach useful for decision making?

5. Was the conference a professional growth experience?

Positive responses of the regular education teachers ranged from $66.6 \%$ (perception of the problem-solving nature of conferences) to $100 \%$ (multidisciplinary exchange, provision for local school district input, and professional growth experience, and useful to decision making). Overall, $88.8 \%$ of the special education teachers' responses and $94 \%$ of the regular and Chapter 1 teachers' responses were positive in regard to case conference activities.

\section{Teacher Feedback: The Diagnostic and Training Classroom}

Approximately $87 \%$ of the teachers who visited the diagnostic and training classroom responded positively regarding the inservice training experience (see Table 1). Additional data indicate that $90 \%$ thought they learned about academic intervention; $85 \%$ judged the classroom observation to be a worthwhile educational experience.

\section{Teacher Feedback: Liaison Consultation}

Following participation in the diagnostic classroom, the liaison delivers written suggestions (educational alternatives) to teachers and offers various forms of support for helping them implement strategies of their choice. Teacher feedback revealed that approximately $97.5 \%$ of all teachers $(\mathrm{N}=23)$ found the written recommendations comprehensive and helpful (see Table 1) and stated that they modified their teaching as a consequence of their involvement with the MDTP. On the average, teachers reported that they attempted at least four of the recommended teaching strategies or suggested instructional materials in their classrooms. Additional data indicate that many teachers $(50 \%)$ requested follow-up (i.e., technical assistance) beyond that initiated to the local district by the liaisons.

\section{Parent Feedback}

Table 1 also contains a summary of parent responses to the follow-up survey. Of the parent respondents $(\mathrm{N}=10)$, 90\% stated that the individual diagnostic assessment information (e.g., speech and language, medical) was useful. All parents reported that the diagnostic classroom benefited their children and affected them positively in the long run. Many parents (90\%) indicated they were still using some teaching or behavior management techniques they had learned from the MDTP.

During the 1987-88 academic year, data were collected from parents regarding the monthly parent meetings conducted in the evenings by MDTP staff members. On a scale of 1 to 6 , with 1 being poor and 6 being excellent, the parents responded to 10 questions. The data, generated from seven meetings, include a total of 60 responses. The seven sessions covered the following topics: instructional games, living with children, language activities to use at home, precision teaching, siblings, computer uses at home, and attention deficit disorder. The 10 questions and respective evaluation data are presented in Table 2. An inspection of Table 2 indicates that the parents evaluated the MDTP evening parent program in a highly positive manner. All sessions were ranked positively across the ten questions.

\section{Services to Children}

The diagnostic classroom uses data-based teaching procedures to validate effective interventions for children with diverse academic, behavioral, and medical problems. A vital component of MDTP, the classrom serves approximately 35 students during the regular school year and 50 during the summer session.

\section{Follow-Up Study}

Follow-up data, shown in Table 3, on a random sample of students $(\mathrm{N}=13)$ reveal that 2 to 4 years after participating in the MDTP, students improved or maintained performance in five school-related areas: absenteeism, standard scores 
TABLE 1

Follow-Up Data on Inservice Teachers and Parents (1981-84)

\begin{tabular}{|c|c|c|c|}
\hline \multirow[b]{2}{*}{ Area Evaluated } & \multirow[b]{2}{*}{ Summary of Responses } & \multicolumn{2}{|c|}{ Feedback from Teachers } \\
\hline & & $\begin{array}{l}\text { Special Ed. } \\
(\mathrm{N}=10) \\
\%\end{array}$ & $\begin{array}{c}\text { Regular Ed. } \\
\begin{array}{c}(\mathrm{N}=13) \\
\%\end{array} \\
\end{array}$ \\
\hline \multirow[t]{5}{*}{ Case Conferences } & Multidisciplinary exchange & 100 & 90 \\
\hline & Able to give input & 100 & 100 \\
\hline & Problem solving & 66.6 & 80 \\
\hline & Useful to decision making & 88.8 & 100 \\
\hline & Professional growth experience & 88.8 & 100 \\
\hline Diagnostic Classroom & $\begin{array}{l}\text { Rated their learning experience positive with regard to } \\
\text { observing the classroom, learning about management, } \\
\text { academic interventions, and learning per se }\end{array}$ & 88.4 & 85.2 \\
\hline Educational Alternatives & $\begin{array}{l}\text { Found MDTP suggestions helpful and modified } \\
\text { their teaching as a result }\end{array}$ & 95 & 100 \\
\hline New Strategies Tried & Attempted new strategies based on MDTP suggestions & 4.4 & 4.5 \\
\hline $\begin{array}{l}\text { Test Results (written } \\
\text { and follow-up) }\end{array}$ & $\begin{array}{l}\text { Found the terms helpful; provided } \\
\text { professional growth }\end{array}$ & 84.4 & 87.8 \\
\hline
\end{tabular}

Parent Opinion

Area Evaluated Rate of Positive Responses to Total

Usefulness of assessments

Still using techniques learned at MDTP

$9 / 10$

$9 / 10$

Diagnostic classroom benefits

$10 / 10$

positive

yes

yes

on achievement tests, basal series progress, school grades, and conduct. Given that the demands for school success increase in the later grades, these long-term data on the students' progress are most encouraging.

Table 3 also contains a summary of parent responses regarding the progress of their children following MDTP participation. All parents reported that the diagnostic classroom benefited their children and affected them positively over time; 8 of 9 believed their children were doing better at home; and 6 of 10 believed their children were doing better at school. All parents thought their children were doing the same or better in getting along with (a) the family, (b) teachers, and (c) peers.

\section{Diagnostic Classroom Study}

To examine the effectiveness of the diagnostic classroom, Levins (1988) studied the progress of all learning disabled (LD) students who were enrolled for a 3- to 6-week session during the period from January, 1982 to December, 1987. The Brigance Inventory of Basic Skills, the Brigance Inventory of Essential Skills, and precision teaching probes were administered prior to diagnostic classrooom interventions, to obtain pretest scores. Upon completion of the 3- to 6-week session, the students were tested with the same instruments, to obtain posttest scores. Students worked on skills tailored to their individual needs. Therefore, the number of students for each specific skill varies. As presented in Table 4, word recognition and mathematics are grade-level scores; punctuation, sight words, direction words, and money skills are percentage scores; and see/write addition facts, see/write subtraction facts, think/write uppercase letters, and see/say sight words are rate correct and rate error scores per minute.

Moreover, learning rates for word recognition and mathematics were obtained. These rates were calculated by dividing the grade-level gain (in months with $1 / 10$ grade level equaling 1 month) by 1.5 (the number of months of diagnostic classroom participation). A comparison of the 
TABLE 2

Parent Feedback on 1987-88 Monthly Parent Meetings

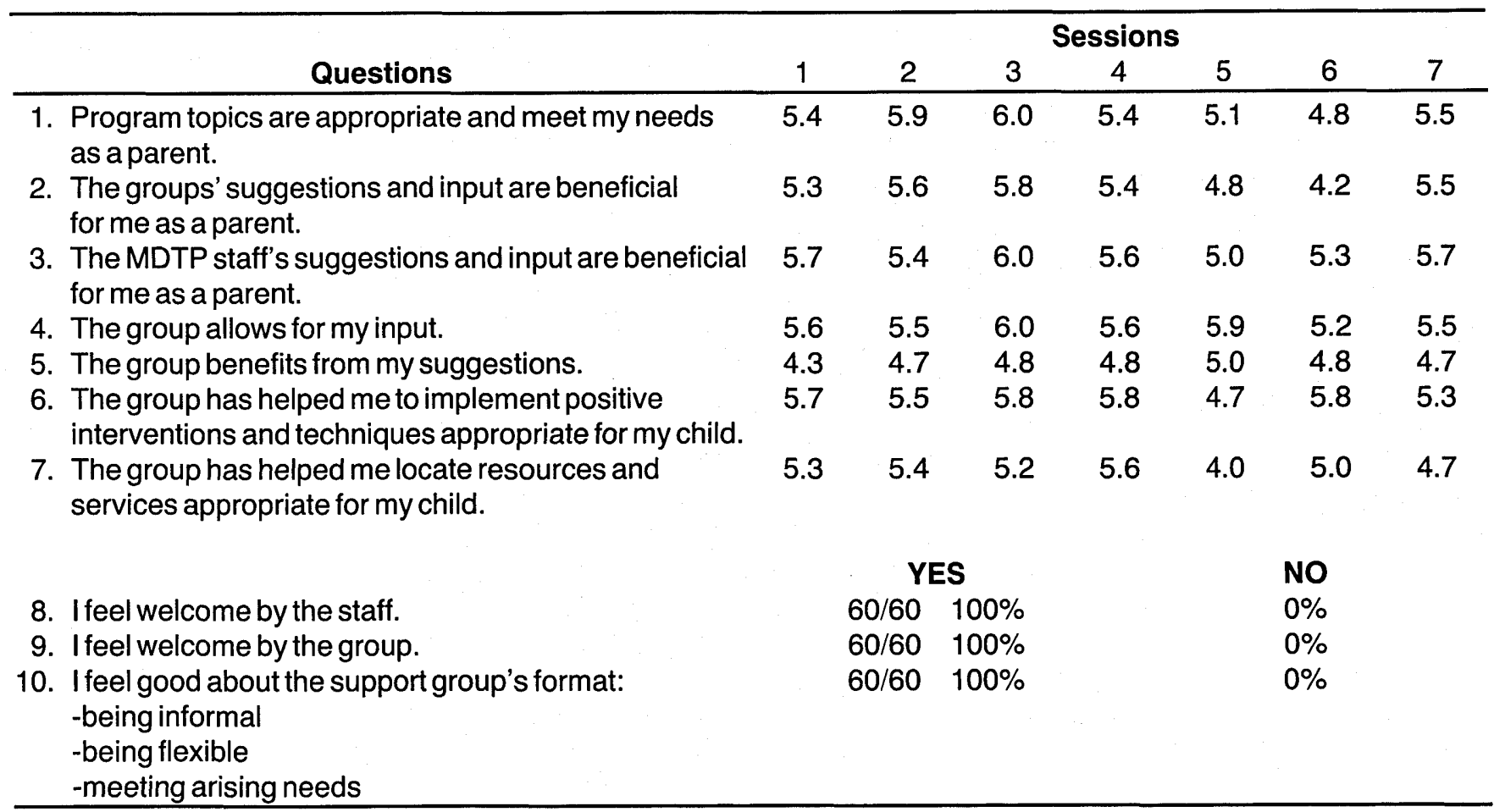

average of these rates for each student and learning rates of students prior to enrollment (calculated by multiplying pretest grade-level scores by 10 and dividing by the total number of months in school) is charted in Figure 1. In essence, Figure 1 compares the students' learning rate per month prior to MDTP to their learning rates while enrolled in the MDTP classroom.

An inspection of Table 4 indicates that academic gains are very positive. Word recognition improved .55 grade level or 5.5 months during the 1.5-month diagnostic classroom session. Mathematics growth was an impressive 1.1 grade level or 11 months during the session. Percentage improvement occurred in all four academic areas, with the most growth in direction words (36\%) and the least growth in sight words $(13 \%)$. The rate data indicate that students at least doubled their corrects across all four academic areas and practically eliminated their errors.

As reported in Figure 1, the prior monthly learning rates (word recognition .55 and mathematics .74) and during MDTP learning rates (word recognition 2.87 and mathematics 6.83) reflect a dramatic difference in favor of MDTP. Although a stronger design and larger sample size would have strengthened the impact of the gains reported by Levins (1988), it is apparent from the collective data presented that the diagnostic classroom is having a very positive impact on the academic growth of LD students.

\section{Services to University Students}

Preservice is a vital component of MDTP. It occurs through formal course work, attendance and participation in the case conferences and diagnostic classroom, enrollment in practica and independent studies, and individual consultation with MDTP liaison and classroom teachers. An examination of MDTP preservice activities for the fiscal year July 1,1986 , to June 30,1987 , provides a descriptive evaluation of the preservice component. Inspection of Table 5 reveals that a substantial number of special education, speech/language, and medical students received training. In addition, MDTP staff participated in 28 university courses that enrolled approximately 560 students. Finally, MDTP staff conducted 64 workshops during the year, involving approximately 2,250 trainees.

A random sample of the evaluations of 45 special education students who participated in intensive practica in the diagnostic classroom from 1982 to 1985 reflect positive results. The evaluations involved rating three statements on a 5-point Likert scale, with 1 being "very little" and 5 being "significant amount." The student evaluation forms were completed anonymously. The statements and respective ratings follow: 
TABLE 3

\section{Follow-Up Data on Randomly Selected Students Enrolled in Diagnostic Class}

\begin{tabular}{lcl}
\hline & $\begin{array}{c}\text { Student Data } \\
\text { Rate of Positive } \\
\text { Area Evaluated }\end{array}$ & \multicolumn{2}{c}{\begin{tabular}{c} 
Responses to Total \\
\hline Absenteeism
\end{tabular}} & $8 / 11$ same or improved \\
Standard Scores & $6 / 7$ & same or improved \\
Basal Series Progress & $13 / 13$ improved \\
Grades & $12 / 13$ same orimproved \\
Conduct & $8 / 9$ & same orimproved \\
\hline
\end{tabular}

\section{Parent Opinion}

\begin{tabular}{|c|c|c|}
\hline Area Evaluated & $\begin{array}{r}\text { Ra } \\
\text { Resp }\end{array}$ & $\begin{array}{l}\text { e of Positive } \\
\text { onses to Total }\end{array}$ \\
\hline $\begin{array}{l}\text { Child still positively } \\
\text { affected by MDTP }\end{array}$ & $10 / 10$ & yes \\
\hline Child doing better at home & $8 / 9$ & yes \\
\hline Child doing better at school & $6 / 10$ & yes \\
\hline $\begin{array}{l}\text { Child getting along with } \\
\text { others }\end{array}$ & $10 / 10$ & same or better \\
\hline
\end{tabular}

1. Rate your experience in the project in terms of knowledge acquired. (Range of responses $=4$ to 5 , Mean $=4.80$ )

2. Rate your experience in the project in terms of skills acquired. (Range of responses $=4$ to 5 , Mean $=4.71$ )

3. Rate your overall experience in the project. (Range of responses $=4$ to 5 , Mean $=4.88$ )

Student comments on the evaluations were very positive and included statements such as: "My experience in the MDTP has been great! I can't believe how much I've learned." "I recommend this practicum setting to anyone. Thanks for the opportunity." "I learned more than I ever imagined."

Being in a university setting, it is imperative that the MDTP maintain a viable preservice program. The preservice activities and feedback suggest that MDTP is a valuable training resource to university students across a variety of disciplines.

\section{Research and Dissemination}

In service-oriented programs, initiating and maintaining viable research efforts is often difficult. Because the MDTP is university-based, it is important that applied research be conducted to validate services and involve the resources (e.g., faculty, students) of the university community. Fortunately, the university setting provides both resources and impetus to conduct research programs. Moreover, the teaching and scholarship mission of the university promotes and facilitates dissemination activities.

\section{Research}

As of June 30, 1987, MDTP staff members have published over 60 articles in professional journals. Also, MDTP staff members have written a series of monographs, which now totals 18. Many of these publications feature data gathered in project activities such as academic interventions, team functioning, assessment, parent training, and consultation.

A series of studies that has produced encouraging results is in the area of teaching math to exceptional students. As of spring 1988, 10 studies have been completed in the math research strand. These have included one doctoral dissertation and five masters research projects involving six university students, five MDTP staff members, nine university faculty members, and four school district classroom teachers. Researchers in each of the math studies examined the effectiveness of the concrete-semiconcrete-abstract sequence in teaching math skills. To date, each investigator has reported that the math sequence was effective in promoting skill acquisition and retention. These results have been obtained across math skills (i.e., place value, subtraction facts, addition facts, fractions, multiplication facts, division facts, and coin sums to 50) within a variety of settings.

The math research strand demonstrates that a universitybased multidisciplinary team can initiate and maintain a research effort that promotes scholarship and involvement of a team of people. In essence, this research effort provides the university with a viable model for applied research. Finally, a series of studies also has been conducted in selfmanagement, coaching, and peer teaching.

\section{Dissemination}

In addition to disseminating research through articles and monographs, MDTP staff members share much information through texts, conference presentations, and workshops. For example, during the 1986-87 fiscal year, the MDTP staff conducted 33 workshops, made 31 conference presentations, and published two books.

A significant dissemination event occurred in January, 1988. The MDTP planned and hosted a conference titled "Strategies for Success: Linking Disciplines to Effect Change in Children." Altogether, 325 individuals from various disciplines attended the conference. All MDTP professional staff members gave presentations at the conference. Of the 138 participants who returned evaluation forms, there were 70 teachers, 11 psychologists, 21 speech/language clinicians and 36 others (administrators, parents, social workers, students, etc.). Feedback on the evaluations was 
TABLE 4

Pre- and Posttest Data of Students in Diagnostic Class

\begin{tabular}{|c|c|c|c|c|c|c|}
\hline Skill & $\begin{array}{l}\text { Gra } \\
\text { Pre } \\
\text { Mea }\end{array}$ & $\begin{array}{l}\text { le Level S } \\
\text { est } \\
(1)\end{array}$ & $\begin{array}{r}\text { ores Fro } \\
\text { Pos } \\
\text { Mea }\end{array}$ & $\begin{array}{l}\text { Brigan } \\
\text { est } \\
(2)\end{array}$ & $\begin{array}{c}\text { Gain Score } \\
\text { M2-M1 }\end{array}$ & $\begin{array}{l}\text { Months Growth } \\
\text { in } 1.5 \text { months }\end{array}$ \\
\hline $\begin{array}{l}\text { Word Recognition }(N=36) \\
\text { Mathematics }(N=18)\end{array}$ & & & & & $\begin{array}{r}.55 \\
1.10\end{array}$ & $\begin{array}{r}5.5 \\
11.0\end{array}$ \\
\hline \multicolumn{7}{|c|}{ Percentage Scores From Brigance } \\
\hline $\begin{array}{l}\text { Punctuation }(N=12) \\
\text { Sight Words }(N=11) \\
\text { Direction Words }(N=13) \\
\text { Money Skills }(N=7) \\
\end{array}$ & & $\begin{array}{l}34 \\
32 \\
32 \\
57 \\
\end{array}$ & & $\begin{array}{l}56 \\
45 \\
68 \\
84 \\
\end{array}$ & & $\begin{array}{l}22 \\
13 \\
36 \\
27 \\
\end{array}$ \\
\hline Skill & $\begin{array}{r}\text { Rate Co } \\
\text { Pre } \\
\text { Correct }\end{array}$ & $\begin{array}{l}\text { rect and } \\
\text { est } \\
\text { Errors }\end{array}$ & $\begin{array}{r}\text { rror Sco } \\
\text { Pos } \\
\text { Correct }\end{array}$ & $\begin{array}{l}\text { S From } \\
\text { test } \\
\text { Errors }\end{array}$ & $\begin{array}{l}\text { bes } \\
\text { Gain Correct }\end{array}$ & $\begin{array}{l}\text { Decrease in } \\
\text { Errors }\end{array}$ \\
\hline $\begin{array}{l}\text { See/Write Add. Facts }(N=29) \\
\text { See/Write Sub. Facts }(N=30) \\
\text { Think/Write Uppercase }(N=15) \\
\text { See/Say Sight Words }(N=19)\end{array}$ & $\begin{array}{l}17 \\
13 \\
18 \\
28\end{array}$ & $\begin{array}{l}1 \\
1 \\
1 \\
9\end{array}$ & $\begin{array}{l}34 \\
29 \\
37 \\
58\end{array}$ & $\begin{array}{l}0 \\
0 \\
0 \\
2\end{array}$ & $\begin{array}{l}17 \\
16 \\
19 \\
30\end{array}$ & $\begin{array}{l}1 \\
1 \\
1 \\
7\end{array}$ \\
\hline
\end{tabular}

extremely positive, with high ratings on program organization, topic relevance, and presenter competence/delivery. The conference now is being planned as an annual event.

\section{IMPLICATIONS}

Chalfant (1987) has estimated that approximately $20 \%$ to $30 \%$ of the school-age population, or at least $8,000,000$ students, is experiencing difficulty progressing in school because of learning problems. This condition exists in spite of a proliferation of legislation and federally funded "special," "compensatory," and "remedial" education programs over the past two decades. Given the high number of school failures, it behooves local, state, and federal governments to join with educators and related professionals in continuing to explore ways to provide success to the many students who need special help.

The success of the MDTP across key areas such as services to children, preservice education, inservice training, parent training, and research suggests that regional-level, university-based multidisciplinary diagnostic-training centers deserve consideration in designing an overall program to serve exceptional students. Some of the potential benefits of these centers are discussed next.

\section{Center of Excellence for Teaching and Training}

Because of budget constraints, different levels of competence among teachers, and the failure or delay to integrate what is known about effective teaching into the classroom, finding exemplary programs for exceptional students is often difficult. A university-based diagnostic center has the potential to initiate and maintain a "best practices" instructional program for exceptional students. This is possible because the program staff members have control of key factors such as curriculum for individual children, multidisciplinary input, the competence of instructional staff, inservice training, and a program evaluation system.

An examination of the success of students enrolled in the diagnostic classroom indicates that, given the proper learning environment, children with diverse learning problems can learn at impressive rates. This factor alone should encourage educators and parents and raise the consciousness of governmental, community, and educational leaders to support educational programs at a level that allows exceptional students to succeed. Some of the specific benefits are:

1. MDTP teachers are continuously serving as consultants, role models, child advocates, and teachers of students with a myriad of diverse medical, behavioral, and learning 


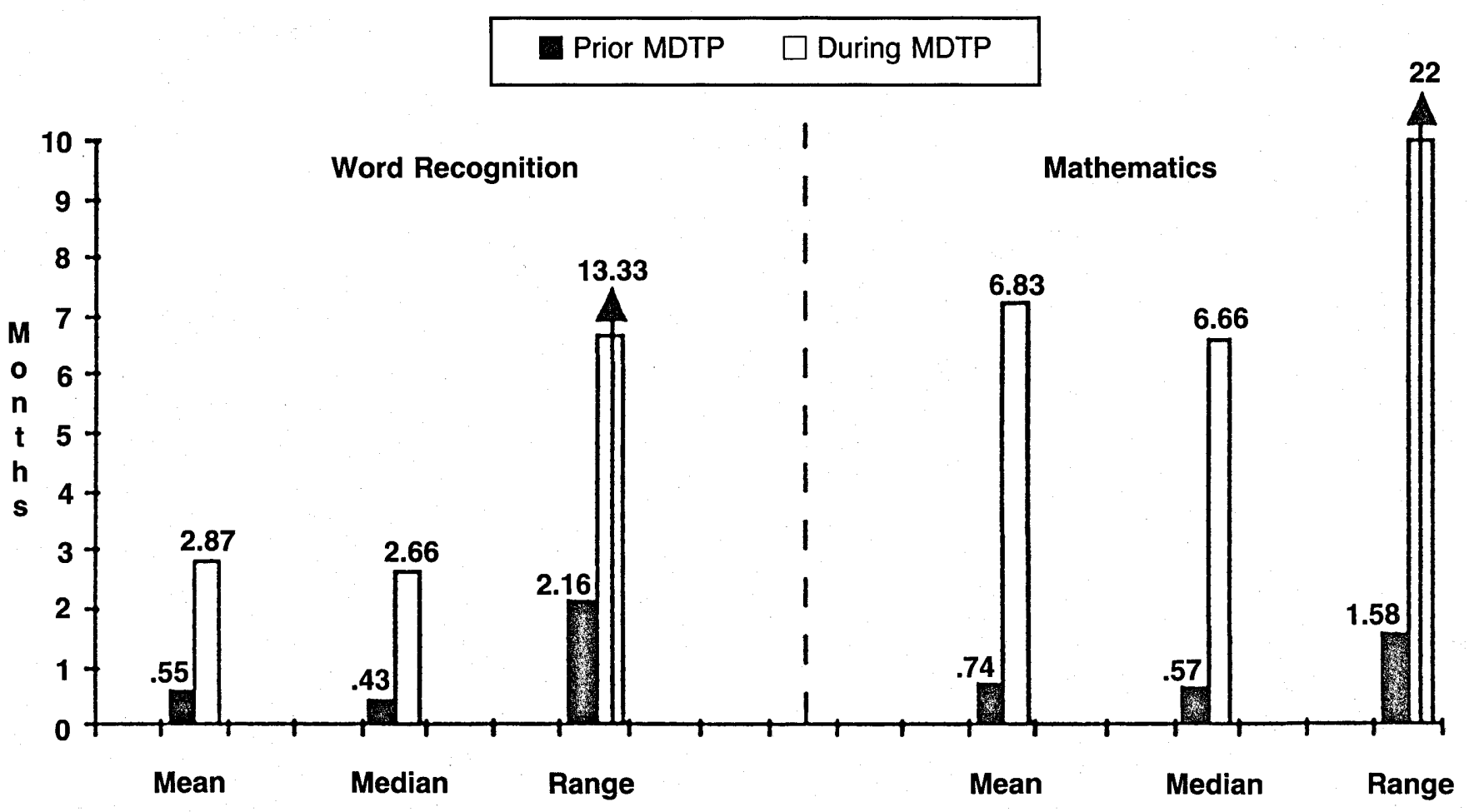

FIGURE 1

Monthly Growth Rates

problems. Periodically, school-based special education teachers require multidisciplinary expertise. Moreover, they need a constant support system to help with solving difficult instructional problems. A diagnostic teaching center offers these teachers a much needed resource and support system.

2. A multidisciplinary diagnostic teaching center is able to work with school-based teachers to initiate effective instructional techniques for individual students. These techniques often work with other students, and a positive ripple effect occurs throughout the curriculum. For example, the data (in Table 1) indicate that school-based teachers report using an average of 4.5 new techniques after consulting with MDTP staff. The multidisciplinary team-teacher relationships provide an excellent format for initiating teacher coaching programs. Showers (1985) reports that the effects of coaching are impressive and stresses that it provides the follow-up essential for training new skills and strategies.

3. A university-based multidisciplinary diagnostic center provides a classroom setting in which to apply the latest findings about effective teaching. This enables university students, through observation and practicum experiences, to observe the application of current instructional technology. These experiences improve the skill development of university students and enhance the quality of preservice education. As reported earlier, the evaluation feedback of university students regarding their experience with MDTP was very positive.

4. A university-based diagnostic teaching center provides a setting for implementing the diagnostic teaching process (e.g., 3-6 weeks). This teaching process enables the team to select and validate instructional procedures for exceptional students who make minimal or little progress in special education settings. The success of diagnostic teaching provides all involved with a meaningful learning experience. For example, it often demonstrates the importance of teamwork (especially brainstorming), the value of daily assessments of student performance, the power of effective teaching practices, and the effectiveness of behavior management and motivation techniques. Finally, the success of this process often instills a sense of pride and confidence about teaching in all parties involved.

5. A university-based multidisciplinary diagnostic teaching team is able to work with parents to facilitate the growth 


\section{TABLE 5}

Number of Preservice Professionals Trained: Types and Number of Training Modes $7 / 86-6 / 87$

\begin{tabular}{|c|c|}
\hline \multicolumn{2}{|c|}{ Number of Student Trainees } \\
\hline 192 & $\begin{array}{l}\text { Observations-Case Conferences, Classroom, } \\
\text { Parent Meetings }\end{array}$ \\
\hline 48 & Medical Students \\
\hline 15 & Pediatric Residents \\
\hline 79 & $\begin{array}{l}\text { Master's Theses/Practica/Lab for Special } \\
\text { Education Students }\end{array}$ \\
\hline 6 & Speech/Language Master's Students \\
\hline 1 & Psychology Intern \\
\hline
\end{tabular}

\section{Telephone Contacts}

152 Practicum Students

\section{Conferences/Face-to-Face Meetings}

425 Practicum Students

91 Pediatric Residents

of their children. Also, it can be an impetus to developing a cooperative relationship with school personnel.

6. A university-based multidisciplinary diagnostic center provides an excellent setting for conducting applied research. Specifically, it affords the opportunity to involve practitioners and researchers in an ongoing programmatic research program (e.g., math strand in MDTP).

\section{A Model of Multidisciplinary Teamwork}

The MDTP multidisciplinary model appears to incorporate several factors that various authors associate with successful interdisciplinary teams. More specifically, as advocated by Yoshida et al. (1978) and Ysseldyke et al. (1981), the MDTP has a structured separation of activities within the case conference and within the overall assessment-treatment process. Integration of assessment and intervention is an important goal for interdisciplinary teams, achieved within the MDTP primarily by three formal mechanisms: the case conference, the diagnostic and training classroom, and the liaison consultant functions.

Frequently cited problems, such as the lack of interdisciplinary collaboration and unsystematic collection of diagnostic information associated with interdisciplinary teams (Pfeiffer, 1980), are overcome by MDTP procedures that promote sharing and standard data presentation among disciplines during the initial diagnostic step (i.e., the diagnostic clinic and case conference). For instance, the school psychologist and educational diagnostician gather information regarding the child's functioning at school and in the home before selecting formal or informal tests to administer. The MDTP liaison teacher not only has compiled data gathered from the cumulative folder and interviews but also has collected observational data on both the student and the school setting. Thus, the liaison teacher expects to give input into the testing process. Armed with information the examiners will understand, the liaison consultant helps the school psychologist and educational diagnostician determine which strengths or weaknesses may require further investigation.

Similarly, information relevant to the pediatrician may be uncovered by the liaison prior to the physical/neurological exam. A more common cooperative effort, however, usually is found among the physician, liaison, MDTP teachers, and parents, after visiting the diagnostic clinic, when medication may be initiated or changed. In accordance with the admonishment of Ysseldyke et al. (1981) to consider everyday behavior and to link assessment to the student's problem, these professionals work together to observe the functional effects of medication on a child and supply the physician with information critical to making sound decisions.

Being called upon to participate or lead multidisciplinary staffings is becoming common for the pediatrician, yet few have been trained in this role (Bennett, 1982). In this regard, the MDTP provides inservice training not only for educationrelated professionals but for professionals in health-related fields, too.

Since its beginning, the MDTP has developed procedures and guidelines that promote the team process and, consequently, improve functioning at all levels—child services, preservice, inservice, parent training, and research. Some benefits of a university-based multidisciplinary team are listed below.

1. The university-based multidisciplinary team is a potentially untapped, cost-effective resource for preservice and inservice training of regular and special educators in Colleges or Departments of Education.

2. The university-based multidisciplinary program may serve as a prototype model for improving coordination and communication among disciplines and within school units (e.g., consultation between regular and special education teachers).

3. The multidisciplinary case conference/staffing can be an instructive and supportive environment in which trainees and teachers may acquire and try out consultation and coaching skills.

4 . The exemplary multidisciplinary team will demonstrate to participants that (a) the sum of knowledge and experience of the team outweighs that of the individual, (b) a greater number of possible approaches will be generated to solve a problem, (c) there is better communication of decisions when they are executed within the group, and (d) more efficacious 


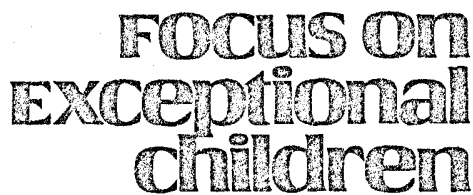

use of the educators' talents is likely to occur as a result of effective teamwork.

5. Employing the liaison consultant, a professional teacher, as the case conference leader facilitates participation, collaboration, and trust.

6. Use of a democratic leadership style and participative problem-solving enhances involvement and cross-disciplinary exchange.

7. Use of a consistent case conference agenda, a predetermined problem-solving format, and visual aids reduces ambiguity and focuses participant attention.

8. Gaining final consensus on the recommendations and responsibilities of team members is conducive to improved follow-through.

\section{CONCLUSION}

The University of Florida Multidisciplinary Diagnostic and Training Program (MDTP), operative for 7 years, represents an interdisciplinary approach that has expanded its functions and attempted to make those functions more useful for exceptional students, university students, school-based teachers, and parents. The MDTP has established training and intervention goals and procedures for achieving these goals that extend well beyond the traditional assessment focus of hospital and university multidisciplinary efforts.

Even though all direct (e.g., a student's acquisition of a specific skill) and indirect (e.g., how a pediatrician can help a parent handle a school-related problem at some future date) effects are impossible to evaluate, the MDTP has begun to install systematic program evaluation procedures for assessing such effects. Currently some outcomes (e.g., changes in reading rate) are objectively measured, while others (e.g., parent satisfaction) are being evaluated by more subjective means. The collective data support this multidisciplinary approach, one that actively involves professionals from many disciplines. Indeed, the model appears to promote cooperative independence (i.e., interdependence) among participants-the highest level of maturation a group may achieve, according to Bergevin and McKinley (1965).

Experience of the MDTP staff supports the merit of developing a university-based multidisciplinary team with shared goals-e.g., assessment, intervention, and training. A singular unifying philosophy of wholehearted commitments to serve children, families, and school district personnel and train competent professionals makes the mission not only possible to achieve but rewarding for all those involved.

\section{REFERENCES}

Armer, B., \& Thomas, B. (1978). Attitudes toward interdisciplinary collaboration in pupil personnel services teams. Journal of School Psychology, 16(2), 167-176.

Barbrack, C. (1978). Interdisciplinary decision making: A response to the challenge of PL 94-142. School Psychology in New Jersey, 19, 31-37.

Bass, B., \& Leavitt, H. (1963). Some experiments in planning and operating. Management Science, 9, 574-585.

Bennett, F. (1982). The pediatrician and the interdisciplinary process. Exceptional Children, 48(2), 306-314.

Bergevin, P., \& McKinley, J. (1965). Participation training for adult education. St. Louis: Bethany Press.

Chalfant, J. (1987). Providing services to all children with learning problems: Implications for policy and programs. In C. Bos \& S. Vaughn (Eds.), Issues and future directions for research for the learning disabled. Boston, MA: Little, Brown/College-Hill Press.

Levins, J. (1988). A comparison and analysis of pre and posttest scores of learning disabled students enrolled in MDTP classroom. Unpublished master's project, Department of Special Education, University of Florida, Gainesville.

Mercer, C. (1987). Beyond traditional assessment. In C. Bos \& S. Vaughn (Eds.), Issues and future directions for research for the learning disabled. Boston, MA: Little, Brown/College-Hill Press.

Pfeiffer, S. (1980). The school-based interprofessional team: Recurring problems and some possible solutions. Journal of School Psychology, 18(4), 388-394.

Pryzwansky, W., \& Rzepski, B. (1983). School-based teams: An untapped resource for consultation and technical assistance. School Psychology Review, 12(2), 174-178.

Ross, J., Mercer, C., Hendrickson, J., Peterson, S., \& Hughes, C. (1985). The multidisciplinary team: Reaching beyond traditional assessment. International Journal of Partial Hospitalization, 3(2), 117-129.

Showers, B. (1985). Teachers coaching teachers. Educational Leadership, 42(7), 43-48.

Yoshida, R., Fenton, K., Maxwell, J., \& Kaufman, M. (1977). Group decision making in the planning team process: Myth or reality? Journal of School Psychology, 16(3), 237-244.

Yssekdyke, J., Algozzine, B., \& Allen, D. (1981). Participation of regular education teachers in special education team decision making: A naturalistic investigation. Elementary School Journal, 82(2), 160-165.

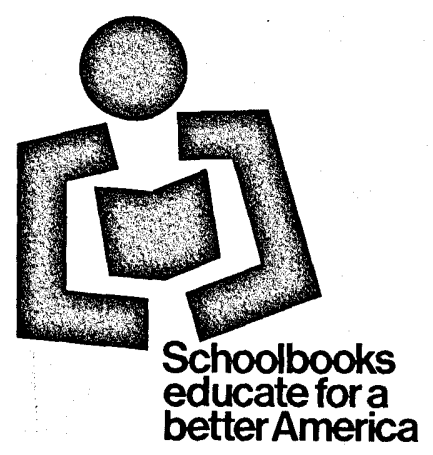

The Association of American Publshers 